\title{
Clinical use of CCR5 inhibitors in HIV and beyond
}

\author{
Bruce L Gilliam ${ }^{\dagger}$, David J Riedel ${ }^{\dagger}$, Robert R Redfield ${ }^{*}$
}

\begin{abstract}
Since the discovery of CCR5 as a coreceptor for HIV entry, there has been interest in blockade of the receptor for treatment and prevention of HIV infection. Although several CCR5 antagonists have been evaluated in clinical trials, only maraviroc has been approved for clinical use in the treatment of HIV-infected patients. The efficacy, safety and resistance profile of CCR5 antagonists with a focus on maraviroc are reviewed here along with their usage in special and emerging clinical situations. Despite being approved for use since 2007, the optimal use of maraviroc has yet to be well-defined in HIV and potentially in other diseases. Maraviroc and other CCR5 antagonists have the potential for use in a variety of other clinical situations such as the prevention of HIV transmission, intensification of HIV treatment and prevention of rejection in organ transplantation. The use of CCR5 antagonists may be potentiated by other agents such as rapamycin which downregulate CCR5 receptors thus decreasing CCR5 density. There may even be a role for their use in combination with other entry inhibitors. However, clinical use of CCR5 antagonists may have negative consequences in diseases such as West Nile and Tick-borne encephalitis virus infections. In summary, CCR5 antagonists have great therapeutic potential in the treatment and prevention of HIV as well as future use in novel situations such as organ transplantation. Their optimal use either alone or in combination with other agents will be defined by further investigation.
\end{abstract}

\section{Introduction}

After the discovery that HIV gains entry to cells by binding the CD4 receptor [1], research initially focused on development of inhibitors that could block this binding step. However, this line of inquiry led to the realization that CD4 receptor binding was necessary but not sufficient for HIV to enter the host cell; a second step a coreceptor - was also required. The coreceptors CCR5 (CC chemokine receptor 5) [2-5] and CXCR4 (CXC chemokine receptor 4) [6-9] were discovered a few years later. Identification of the three natural ligands of CCR5 - (Regulated upon Activation, Normal T-cell Expressed, and Secreted [RANTES], macrophage inflammatory protein-1 alpha [MIP-1 $\alpha$ ], and macrophage inflammatory protein-1 beta [MIP-1 $\beta]$ ) - as potent inhibitors of HIV [10] quickly led to research to find synthetic compounds to block the receptor and thus prohibit viral entry.

CCR5 is expressed on a number of cells including activated $\mathrm{T}$ lymphocytes, macrophages, and dendritic cells [11], and CCR5-tropic HIV-1 strains are

\footnotetext{
* Correspondence: rredfield@ihv.umaryland.edu

+ Contributed equally

Institute of Human Virology, University of Maryland School of Medicine, 725 West Lombard St., Baltimore, 21201 Maryland, USA
}

predominantly involved in transmission of the virus [12]. Mutation in the CCR5 gene leading to a 32-base pair deletion $(\triangle 32)$ in the CCR5 protein and an absence of CCR5 on the surface of cells causes homozygotes for $\Delta 32$ to be almost completely resistant to HIV-1 infection [13-15]. Additionally, heterozygotes for $\Delta 32$ have delayed HIV disease progression, slower declines in CD4 cell counts, and lower average circulating viral loads [16]. Taken together, this information provided an enticing target for pharmaceutical intervention against HIV-1 infection.

Several products targeted against CCR5 have been developed (Table 1), though only one is currently approved by the U.S. Food and Drug Administration (FDA) for treatment of HIV-1 infection. The pharmaceutical agents active against CCR5 represent a completely new class of antiretroviral drugs, ones that are not antiretrovirals in the strict sense that they are not directed against HIV's various enzymes, but instead block a host cell receptor to diminish HIV's access to the host's cells. Five different CCR5 antagonists - maraviroc, vicriviroc, aplaviroc, INCB009471 and TBR 652 - have been developed and brought to human trials (Table 1). Aplaviroc advancement was halted after results of two Phase IIb trials showed higher than expected rates of

C Biomed Central

C 2010 Gilliam et al; licensee BioMed Central Ltd. This is an open access article distributed under the terms of the Creative Commons Attribution License (http://creativecommons.org/licenses/by/2.0), which permits unrestricted use, distribution, and reproduction in any medium, provided the original work is properly cited. 
Table 1 CCR5 Antagonists in Clinical Trials

\begin{tabular}{cccc}
\hline Product & Mechanism of Action & Company & Status \\
\hline Maraviroc & Non-competitive inhibitor & Pfizer & FDA Approved \\
Vicriviroc & Non-competitive inhibitor & Schering-Plough & Phase III completed \\
Aplaviroc & Non-competitive inhibitor & GlaxoSmithKline & Development discontinued \\
INCB009471 & Non-competitive inhibitor & Incyte & Phase I/lla completed \\
TBR 652 & Non-competitive inhibitor & Tobira & Phase II completed \\
Pro 140 & Antibody & Progenics & Phase II \\
HGS004 & Antibody & Human Genome Sciences & Phase I completed \\
\hline
\end{tabular}

idiosyncratic hepatotoxicity [17]. Vicriviroc is currently in advanced clinical development (Phase III) but has yet to be FDA-approved. Maraviroc was initially approved by the FDA in August 2007 for the treatment of HIVinfected patients experiencing virologic failure due to resistance to other classes of antiretroviral drugs and, subsequently, for the treatment of antiretroviral naïve patients. INCB009471 is an oral CCR5 antagonist with an extended half-life such that it can be given once daily; results from a Phase I and II trials were presented in 2007 [18-20], but the company has decided not to continue further trials. TBR 652 is the fifth new CCR5 antagonist, and Phase I trial results were presented at a conference in early 2010 [21,22]. The novelty of this class of therapeutics is that this is the first class of antiHIV drugs that focus exclusively on host cellular pathways and not on direct inhibition of viral enzyme mechanisms.

Two other products in development are antibodies to the CCR5 receptor: PRO 140 and HGS004. PRO 140 is a humanized monoclonal antibody that binds to CCR5 and inhibits CCR5-tropic HIV-1 in vitro, and it was recently shown to have potent antiviral activity after a single dose in a Phase Ib monotherapy, dose escalation trial [23]. HGS004 is a human immunoglobulin G4 monoclonal antibody against CCR5 that was also recently tested in a Phase Ib trial [24] that established its safety and in vivo activity against HIV-1.

\section{Mechanism of action}

The process by which HIV infects a host cell is complicated and requires multiple steps. First, the env protein (gp120) on the surface of the virus binds to cellular CD4 receptors. The binding of gp120 leads to a conformational change that exposes the V3 loop; the exposed V3 loop of gp120 then interacts with and binds to a coreceptor on the host cell (either CCR5 or CXCR4) [25]. After the coreceptor is bound, another conformational change in the viral envelope unmasks gp41, which can then insert into the cell's membrane [26]. This step brings the virus into close proximity with the cell, leading to fusion of the virus with the cell [26]. CCR5 antagonists bind to the CCR5 receptor and induce a conformational change to it such that the V3 loop of the viral gp120 is unable to recognize and bind [27-30]. CCR5 antagonists act as allosteric, non-competitive inhibitors of the receptor [25]. CCR5 antibodies work by binding to the extracellular domain of the CCR5 receptor and thereby inhibit interaction between gp120 and the coreceptor $[31,32]$. The result of binding of either an antagonist or an antibody is blockade of the binding interaction which prevents HIV from entering the host cell.

\section{Tropism}

As noted above, the structural change that occurs after CD4 binding leads to exposure of the V3 loop of gp120, and this V3 loop is the area of the envelope that interacts with the coreceptor. The amino acid sequence of the V3 variable domain appears to be the primary determinant of which coreceptor is utilized, i.e. the tropism of the virus [33]. Tropism refers specifically to which coreceptor the virus is designed to utilize to gain entry to host cells. There are 4 categories of HIV-1 tropism: 1) R5 - viruses that bind only to the CCR5 coreceptor; 2) X4 - viruses that bind only to the CXCR4 coreceptor; 3) dual tropism - viruses that can bind to either coreceptor; and 4) mixed tropism - mixed populations that include both R5- and X4-tropic viruses [34,35].

An important relationship between tropism/coreceptor usage and different phenotypic characteristics of the virus has been clearly established. Originally, in vitro studies demonstrated that viruses that were syncytiuminducing on T-cell lines and preferentially replicated on $\mathrm{T}$ lymphocytes were more pathogenic [36]; these features were also correlated with more rapid progression to AIDS and AIDS-related mortality $[37,38]$ and were eventually identified as X4-tropic viruses. Non-syncytium-inducing viruses were noted to replicate best in monocyte-macrophages, have a less virulent clinical course, and correspond to R5-tropic viruses [36-40]. The dynamic nature of HIV tropism has important ramifications for viral transmission and pathogenicity.

R5-tropic viruses predominate in transmission events and infection of new patients as they appear to be more efficiently transmitted than X4-tropic strains [41]; 
additionally, R5-tropic viruses are the principal circulating strain in most patients with early HIV infection [42]. Further evidence, albeit indirect, for the predominance of R5-tropic virus in transmission events comes from the relative resistance to infection of homozygotes for $\triangle 32$ within the CCR5 gene [13-15]. One factor that is likely to play a role in the preferential transmission of R5-tropic strains is the high levels of expression of CCR5 on cells in the genital mucosa [43], thus allowing R5-tropic strains an easier pathway into the host.

$\mathrm{X} 4$-tropic viruses are found much less often in the early stages of HIV infection and are thought to be uncommonly involved with transmission events. However, there is a strong correlation between disease progression to AIDS and coreceptor switching from CCR5 to CXCR4 [40]. It is not entirely clear if this association is causal, i.e. whether CXCR4 receptor usage is pathogenic in leading to clinical progression to AIDS, or if it is simply a consequence of disease progression [44]. Several studies have shown a significantly increased risk of disease progression among patients with X4-tropic or $\mathrm{dual} /$ mixed virus $[42,45,46]$. One of the main (yet still theoretical) concerns about the clinical use of CCR5 antagonists is that they might promote the emergence of X4-tropic viruses that could then go on to accelerate disease progression to AIDS [44]. At this point in time, however, accumulating clinical trial data has not substantiated this fear.

The majority of reports on tropism have come from cohorts of patients infected with HIV-1 subtype B (from the U.S. and western Europe), but new research is emerging to suggest that tropism is also affected by HIV-1 subtype or clade [47]. X4- and mixed tropic viruses appear to be much less common in subtype C-infected patients, and this relationship appears to hold regardless of CD4 cell count or disease stage [48-50]. In subtype C-infected patients, X4-tropic strains have been found after prolonged treatment with ART. Differences in tropism between subtypes $B$ and $C$ could be related to intrinsic differences in the conformation of the V3 loop that could affect the evolution of HIV from R5- to X4tropic [51]. The prevalence of X4-tropic virus also appears to be lower in subtype A [52], but another study found X4-tropic viruses emerging in patients with progression to AIDS [53]. Two small studies with subtype D viruses have found a higher proportion of X4and mixed-tropic viruses $[54,55]$, whereas two small studies of subtype $E$ viruses (more prevalent in southeast Asia) found a similar proportion of R5-, X4-, and mixed tropic viruses as that usually found with subtype $B$ $[56,57]$. Overall, the different subtypes appear to have considerable variability in coreceptor usage, and these differences may have a significant impact on the ability to use CCR5 antagonists in different countries.
From a clinical standpoint, it is imperative to assess viral tropism prior to prescribing a CCR 5 antagonist since the drugs are only effective against R5-tropic viruses. Tropism can be evaluated by genotypic or phenotypic assays. Genotypic assays evaluate the amino acid sequence of the V3 region of gp120, the primary determinant of tropism [58]. Genotypic algorithms to predict viral tropism based on V3 genetic sequences are in development [59], though the results have not always correlated well with phenotypic assays [58]. At this time, genotypic assays have not yet entered into clinical practice.

Phenotypic assays are the most widely used to date in clinical practice; the original test was the Trofile ${ }^{\mathrm{rax}}$ assay by Monogram Biosciences [60]. This test identified X4-tropic strains with a sensitivity of $10 \%$, but it could not differentiate between dual-tropic viruses and mixed populations of X4- and R5-tropic strains $[58,61]$. The Trofile $^{\mathrm{Tt}}$ test had the disadvantages of being expensive and both time- and labor-intensive. Additionally, the fact that not all minority variants are detected with this assay is suboptimal because these strains can lead to treatment failure if undetected.

Failure of the Trofile ${ }^{\mathrm{mx}}$ assay to detect minority variants led to the development of an enhanced sensitivity tropism assay. This assay is able to detect $\mathrm{X} 4$ virus with a sensitivity of $100 \%$ when at least $0.3 \%$ of the viral population is X4-tropic [25]. Using this enhanced assay on previously collected samples from major CCR 5 antagonist trials found that a large number of virological failures were explained by pre-existing X4-tropic virus that was not detected using the original Trofile ${ }^{\mathrm{Tx}}$ assay $[62,63]$. These results reinforce the importance of these assays, though further advances will be necessary before they become standard in routine clinical practice.

\section{Pharmacology}

Maraviroc is administered orally at a usual dose of 300 $\mathrm{mg}$ twice daily and can be given without regard to fasting or fed state. It is rapidly absorbed and has peak drug concentrations between 30 minutes and 4 hours after dosing [64]. At the usual dose of $300 \mathrm{mg}$, bioavailability is $33 \%$ [65], and steady state is reached within 7 days [64]. The drug is widely distributed in the body [65]; preclinical studies with rats found poor penetration into the central nervous system [66], but several small studies in humans demonstrated that maraviroc enters the cerebrospinal fluid at therapeutic levels [67-69]. Tiraboschi et al [67] also found maraviroc levels several times the IC50 in semen. Another study examined the concentration of maraviroc in cervicovaginal fluid and found that drug levels were significantly higher than in plasma at the same time and even 72 hours after oral dosing [70]. This 
result could have important implications for prevention of transmission [see Potential uses below].

Maraviroc is a substrate for the hepatic cytochrome P450 enzyme, CYP3A4 (though it does not inhibit or induce the enzyme itself), as well as P-glycoprotein [65], and so dosing adjustments are required when it is given in combination with other inducers and inhibitors of these enzymes. For inhibitors of CYP3A4 like protease inhibitors, itraconazole, or clarithromycin, the dose of maraviroc is reduced to $150 \mathrm{mg}$ twice daily $[65,71]$. With inducers of CYP3A4 (e.g. efavirenz or rifampin), maraviroc dosing should be increased to $600 \mathrm{mg}$ twice daily $[65,72]$. Dosing does not need to be adjusted when used in combination with other antiretrovirals like tenofovir, nevirapine, enfuvirtide, or raltegravir. Maraviroc concentrations were mildly increased in HIV negative patients with mild and moderate hepatic impairment, though no change in dosing was recommended $[65,73]$. The majority of the drug is excreted unchanged in feces $(\sim 75 \%)$ while about $20 \%$ is excreted in urine [64]. No dosage adjustment is necessary in patients with renal insufficiency. Lastly, maraviroc pharmacokinetics were not found to be altered in men vs. women or in patients of various races/ethnicities [65].

\section{Clinical experience with CCR5 antagonists}

To date there has only been one CCR5 antagonist, maraviroc, approved for the treatment of HIV by the U.S. FDA. This review will therefore focus on maraviroc except where other agents in development have unique characteristics or findings that are important to understand when considering the CCR5 antagonist class.

\section{Efficacy}

The clinical experience with maraviroc (MVC) in HIV infected patients essentially began with two small phase IIa dose escalation studies evaluating the antiviral efficacy of MVC monotherapy over a period of 10 days [74]. These studies evaluated MVC at multiple doses in fed and fasted states compared to placebo in 82 patients. Study participants had to have CCR 5 tropic virus, and the mean baseline CD4 cell count and viral load was 544 cells $/ \mathrm{mm}^{3}$ and $4.62 \log _{10}$ HIV-1 RNA copies/ml, respectively. Of the 63 patients who completed 10 days of therapy, all who received MVC at least $100 \mathrm{mg}$ once or twice daily achieved a mean reduction of viral load at Day 11 of 1.13-1.60 $\log _{10}$ HIV-1 RNA copies/ml. The lower dose groups achieved reductions of 0.43 and $0.66 \log _{10}$ HIV-1 RNA copies $/ \mathrm{ml}$. Interestingly, the maximal viral load decline occurred in several patients after discontinuation of the drug. The median time to viral load nadir was 10-15 days in the different dose groups and viral rebound did not occur immediately.

\section{Treatment experienced patients}

Following the viral load reductions seen in the Phase II studies, maraviroc was evaluated in R5-tropic, treatment-experienced HIV-infected patients [75]. Patients were randomized to receive once or twice daily MVC in combination with an optimized background regimen (OBR) vs. an OBR (the placebo arm) alone in the MOTIVATE (Maraviroc versus Optimized Therapy in Viremic Antiretroviral Treatment-Experienced Patients) trials. These trials were conducted in Canada and the U.S. (MOTIVATE 1) and Australia, Europe and the U.S. (MOTIVATE 2). The results of the trials were pooled for analysis with a total of 1,049 patients (414 MVC once daily; $426 \mathrm{MVC}$ twice daily; 201 placebo (OBR)). It is notable that 955 other patients who were screened for these two studies were excluded due to dual, mixed or CXCR4 tropism. The primary study endpoint, the mean change from baseline in the $\log _{10}$ HIV RNA levels at 48 weeks, was -1.68 for MVC once daily, -1.84 for MVC twice daily and -0.79 for the placebo arm. More importantly, the percentage of patients achieving a viral load of $<50$ copies $/ \mathrm{ml}$ at 48 weeks was $43 \%$ for MVC once daily, $46 \%$ for MVC twice daily and $17 \%$ for the placebo arm, which were statistically significant between each MVC arm and placebo arm $(\mathrm{p}<0.001)$. There were also statistically significant greater mean CD4 cell count increases from baseline in the MVC arms (116 cells/ $\mathrm{mm}^{3}$ in MVC once daily, 124 cells $/ \mathrm{mm}^{3}$ MVC twice daily, 61 cells $/ \mathrm{mm}^{3}$ in placebo) [76]. Subanalyses of the pooled MOTIVATE results revealed a treatment benefit of MVC in combination with OBR when compared to placebo in combination with OBR at screening viral load < or > 100,000 copies/ml, baseline CD4 cell count at all strata $(<50,50-100,101-200,201-350$, and $>350$ cells $/ \mathrm{mm}^{3}$ ), baseline R5 tropism, viral subtype (B vs. non-B), enfuvirtide use, $\Delta 32$ genotype, race, gender, genotypic susceptibility score (GSS), phenotypic susceptibility score, overall susceptibility score, and first use of enfuvirtide, lopinavir-ritonavir or tipranavir-ritonavir [77]. Importantly, these analyses revealed a significant benefit of using an additional active new antiretroviral agent in combination with maraviroc. The results of these studies led to FDA approval of maraviroc for treatment experienced patients.

Those patients who failed screening for the MOTIVATE trials due to dual or mixed tropic virus were offered the opportunity to enroll in a trial evaluating maraviroc in treatment experienced patients with dual, mixed or CXCR4 tropism. In this study 186 patients were randomized to once or twice daily MVC or placebo in combination with an OBR [78], and there were 167 evaluable patients. The primary endpoint, the mean change in viral load from baseline at 24 weeks, was 0.91 , 1.20 and $0.97 \log _{10}$ copies/ml HIV RNA in the once 
daily MVC, twice daily MVC and placebo arms, respectively. Similarly, the proportion of patients with HIV RNA $<50$ copies $/ \mathrm{ml}$ was $21 \%$, and $27 \%$, and $16 \%$ (once daily MVC, twice daily MVC, placebo). Neither noninferiority or superiority of the MVC arms in comparison with the placebo arm was established. Mean CD4 cell count increases from baseline were 60 cells $/ \mathrm{mm}^{3}$ in the once daily MVC arm, 62 cells $/ \mathrm{mm}^{3}$ in the twice daily MVC arm, and 36 cells $/ \mathrm{mm}^{3}$ in the placebo arm at 24 weeks. These differences were statistically significant at 24 weeks, but they were no longer statistically significant at 48 weeks. Overall, there was little virologic or immunologic benefit of maraviroc for the treatment of dual or mixed tropic virus.

Maraviroc has also been evaluated in combination with raltegravir and etravirine in a review of 28 treatment experienced patients with $\mathrm{R} 5$ tropic virus who were started on this combination through expanded access programs. At 48 weeks, all patients had an HIV RNA $<400$ copies/ml and 26/28 (93\%) had an HIV RNA $<50$ copies/ml [79]. There is one case report of a treatment experienced patient with resistant HIV-2 infection that was successfully treated with raltegravir and maraviroc based therapy [80].

\section{Treatment naïve patients}

The success of maraviroc in the treatment experienced trials and the fact that a CCR5 antagonist would have the greatest potential for effectiveness in populations with predominantly CCR5 tropic virus led to an evaluation of MVC in antiretroviral treatment naïve HIV-infected patients. The MERIT (Maraviroc versus Efavirenz in Treatment-Naive Patients) trial was a phase IIb/III, double-blind, placebo-controlled trial that evaluated the safety and efficacy of MVC vs. efavirenz in patients with R5 tropic virus from Australia, Europe, North America, South America and South Africa [63]. Similar to the MOTIVATE trials, patients were initially randomized to receive MVC $300 \mathrm{mg}$ once or twice daily or efavirenz $600 \mathrm{mg}$ once daily in combination with coformulated zidovudine and lamivudine. In contrast to the MOTIVATE trials, only $17 \%$ of the patients screened for the MERIT study were excluded for having $\mathrm{X} 4$ tropic virus. In total, 895 patients were randomized, but an interim analysis found that patients receiving once daily MVC fell outside of the prespecified thresholds for non-inferiority in comparison to efavirenz. The data and safety monitoring board (DSMB) discontinued the once daily MVC arm. This left 721 evaluable patients in the 48 week analysis. In the primary analysis of viral load response $<400 \mathrm{copies} / \mathrm{ml}$, twice daily MVC was non-inferior to efavirenz. However, in the co-primary endpoint of percentage of patients with viral load $<50$ copies $/ \mathrm{ml}$ (65.3\% MVC, $69.3 \% \mathrm{EFV})$, the non- inferiority criterion was not met. There were also lower virologic response rates noted with MVC in high baseline viral load patients, Southern hemisphere patients, black patients and those with non-B subtype virus.

Upon blinded retesting of screening specimens with the enhanced Trofile ${ }^{\mathrm{rm}}$ assay, $15 \%$ of patients had CXCR4 tropic virus. Post hoc analysis of the study with these CXCR4 tropic patients excluded revealed that maraviroc twice daily met the non-inferiority criteria with efavirenz (HIV RNA < 50 copies/ml: $68.5 \%$ MVC vs. $68.3 \% \mathrm{EFV}$ ). Additionally, response rates for maraviroc in the subgroup analyses improved after reanalysis, particularly in those with high baseline viral load. Interestingly, response rates for maraviroc were higher in the Northern hemisphere, and response rates for efavirenz were higher in the Southern hemisphere. The authors attributed these differences to higher adverse event discontinuation rates for efavirenz in the Northern hemisphere and higher default rates for patients receiving maraviroc in the Southern hemisphere. The differences noted by the DSMB for the once daily maraviroc arm when compared to efavirenz that led to discontinuation of that arm were no longer outside the noninferiority thresholds in the post hoc reanalysis. In both the primary and the post hoc reanalysis, CD4 cell count increases were $26-30$ cells $/ \mathrm{mm}^{3}$ higher in the maraviroc arm. Subsequent to the reanalysis of the MERIT data, maraviroc was approved for use in treatment naïve patients by the U.S. FDA.

\section{Resistance}

Although CCR5 antagonists target a host cell receptor, virologic failure and resistance can still occur. Escape from or resistance to CCR5 antagonists can occur through two different mechanisms. The first is through selection of minority variants of CXCR4 or dual/mixed tropic virus. The second is through development of mutations in the gp120 V3 loop, elsewhere in gp 120, or in gp41 [81-83]. In vitro, multiple mutations in the V3 loop can lead to resistance $[82,84,85]$. However, no signature mutations or consistent patterns have been noted in the same or different isolates, and the mutations appear to be context dependent $[82,84,85]$. Also, development of cross-resistance to other CCR 5 antagonists may or may not occur $[81,84-86]$. It is interesting to note that in vitro primary R5 viruses in PBMCs exposed to CCR5 antagonists usually maintain R5 tropism even when CXCR4 receptors are abundantly available $[81,82,84,87]$. It has been proposed that switching to CXCR4 does not occur due to decreased fitness of transitional variants and/or sensitivity to CCR5 antagonists $[85,88,89]$.

In clinical studies, dual, mixed or CXCR4 tropic viruses have been detected in a significant proportion of 
those experiencing treatment failure while receiving maraviroc. Indeed, in the MOTIVATE studies, 57\% (76/ 133) of MVC-treated patients with R5 tropic HIV at baseline who experienced treatment failure had $\mathrm{D} / \mathrm{M}$ or $\mathrm{X} 4$ viruses detected at the time of failure. This is in contrast to 6/95 (6\%) of those who received OBR plus placebo [77]. Similarly, in treatment naïve patients in the MERIT study, 9/29 (31\%) MVC treated patients developed X4 virus in comparison to $0 / 13$ efavirenz treated patients [63]. In contrast, phase 3 studies of vicriviroc in treatment experienced patients (VICTOR E3 and 4) detected $\mathrm{D} / \mathrm{M}$ or $\mathrm{X} 4$ viruses in $13 \%$ (9/71) of patients experiencing virologic failure [90]. However, it is important to note that in the VICTOR studies, $64 \%$ of the subjects had at least three active drugs in their regimen which is in contrast to the maraviroc phase 3 studies in treatment experienced patients where only $37 \%$ of patients had at least three active drugs in their regimen. This data is consistent with findings in the earlier phase II vicriviroc studies in treatment experienced patients $[91,92]$. The results with vicriviroc were also similar in treatment naïve patients where $5 / 26(19 \%)$ virologic failures on the vicriviroc arm developed $\mathrm{D} / \mathrm{M}$ or $\mathrm{X} 4$ viruses [93]. These studies also did not use the newer more sensitive Trofile ${ }^{\mathrm{m}}$ assay, and the patient population was treatment experienced. In one report evaluating four patients who failed vicriviroc therapy, they were found to have the V3 loop mutations associated with failure in minority populations $(0.8-2.8 \%)$ of baseline samples [94]. Another report documented two patients who developed $\mathrm{X} 4$ variants while failing treatment with maraviroc actually had those variants at baseline [95]. Thus, the emergence of $\mathrm{X} 4$ tropic virus in these studies has been demonstrated to be most likely due to the expansion of minority CXCR4 variants present at baseline that were not detected with the Trofile ${ }^{\mathrm{Tm}}$ assay $[85,96]$. Upon cessation of CCR5 antagonist therapy, those patients who switched to dual or mixed tropism while on therapy demonstrate reversion back to R5 tropism $[95,97,98]$. This suggests a fitness cost to dual or mixed tropism in vivo which has not been observed in in vitro culture $[84,86,99]$. Additionally, a post hoc analysis of the MOTIVATE studies demonstrated a low incidence of resistance developing to maraviroc in failing patients who had never achieved viral suppression or had virologic rebound [100]. This data, in light of a report [101] demonstrating that poor adherence with maraviroc was not associated with the development of resistance, suggest that maraviroc has a high barrier to resistance.

The development of mutations in the V3 loop, gp 120, and gp 41 is the second mechanism that may present as clinical resistance to CCR5 antagonists. These mutations allow the resistant virus to bind to the cell's CCR5 receptor that is already bound to maraviroc [84]. This results in a plateau effect of the dose-response curve as increasing drug concentration has no impact due to the ability to utilize the maraviroc-bound receptors. In vitro, the mutations at residues 316 and 323 have been selected by maraviroc [84]. In vivo, mutation combinations involving residues $11,18,10,20,21,22,25$, and 26 have been linked with maraviroc treatment failure $[102,103]$. In this study, it was noted that some dual tropic clones were responsive to maraviroc in vivo. One patient failing treatment with vicriviroc was demonstrated to develop V3 loop mutations which were sufficient to confer resistance [97]. Interestingly, the baseline V3 loop sequences returned once therapy with vicriviroc was discontinued. However, others have questioned the role of these mutations in the V3 loop in the development of resistance to maraviroc [104]. Similarly, an evaluation of the viruses from 323 CCR5 antagonist naïve patients revealed that $7.3 \%$ had mutation combinations previously described with maraviroc resistance [105]. It is possible that the presence of these mutations at baseline may facilitate more rapid resistance in a patient who does not achieve rapid viral suppression.

The implications of resistance to CCR 5 antagonists with respect to other antiretroviral agents has not been well described; however, one report evaluated the implications in vitro and demonstrated that resistance to CCR5 inhibitors may increase the sensitivity of the resistant virus to certain neutralizing antibodies [106]. This finding will need further evaluation in vivo prior to the consideration of developing new entry inhibitor treatment sequencing strategies.

\section{Adverse effects}

The utility of an antiretroviral depends on its safety and tolerability, as exemplified when a case of severe hepatic cytolysis was reported in a patient being treated with the investigational CCR5 antagonist, aplaviroc [17]. Review of aplaviroc trials revealed higher than anticipated elevations in ALT and total bilirubin in the aplaviroc arms [17]. No associations were noted between plasma drug concentrations and liver enzyme elevations. The conclusion of the analysis was that it was an idiosyncratic hepatotoxicity and was intrinsic to the molecule not the class of drugs. Further aplaviroc development was halted due to this report.

A Phase II trial of vicriviroc raised concerns for malignancy when $6 / 90$ subjects in the vicriviroc arms developed malignancies compared to only $2 / 28$ in the placebo arm [91]. In the vicriviroc arms, there were four lymphomas (2 Hodgkin and 2 non-Hodgkin), a gastric adenocarcinoma, and an HPV-relate squamous cell carcinoma. There were no lymphomas in the placebo arm. Concern for CCR5 antagonism leading to EBV reactivation led to evaluation of the four lymphoma patients, 
but EBV reactivation could not be demonstrated [107]. An increased rate of malignancies was not seen in the vicriviroc arms of other studies in both treatment experienced and treatment naïve patients including two Phase III studies with 568 patients treated with vicriviroc $[90,92,93]$.

Despite these initial safety concerns with CCR5 antagonists, maraviroc has had a remarkably clean safety and tolerability profile. The treatment related discontinuation rate due to adverse events was $3 \%$ or less in the maraviroc arms of the trials in treatment experienced patients $[75,78]$. In contrast, in treatment naïve patients, adverse event related treatment discontinuations occurred in $4.2 \%$ of those treated with maraviroc compared with $13.6 \%$ of those treated with efavirenz [63]. Discontinuations occurred earlier with efavirenz (59\% in the first 8 weeks) compared to $40 \%$ of those treated with maraviroc. There were no significant differences in the incidence of serious adverse events and deaths between the maraviroc and the placebo arms in either the treatment experienced or the treatment naïve trials. In the MOTIVATE trials, Category $\mathrm{C}$ events were not different between arms except for esophageal candidiasis which was more common in the maraviroc arms. Category $\mathrm{C}$ events in the MERIT trial were twice as common in the efavirenz arm compared to the maraviroc arm. The incidence of malignancies with maraviroc was not significantly different between arms in treatment experienced patients but twice as many were seen in treatment naïve patients treated with efavirenz vs. maraviroc (Table 2).

In more than 1,300 patients treated with maraviroc in Phase II and III studies, only one case of potentially life-threatening hepatotoxicity has been reported, and isoniazid and/or cotrimoxazole toxicity were actually implicated as etiologic $[63,108]$. No significant differences in Grade 3/4 AST and ALT elevations between treatment arms in either the treatment experienced or treatment naïve patients have occurred $(\sim 3 \%$ for maraviroc and placebo). The effect of maraviroc on lipid profile was more favorable than efavirenz in treatment naïve patients with efavirenz having significantly greater increases in total cholesterol (TC), LDL, and triglycerides [109]. A higher proportion of patients exceeded the National Cholesterol Education Program (NCEP) guidelines for treatment of total cholesterol and LDL, at both week 24 and 48 , in the efavirenz group (14.4\% for $\mathrm{TC}, 6.0 \% \mathrm{LDL})$ compared to the maraviroc group (2.0\% TC, $1.3 \% \mathrm{LDL})$. When the 10 year cardiovascular risk was calculated using the Framingham equation, the risk was consistently higher in the efavirenz group than in the maraviroc group. The authors concluded that maraviroc had minimal effects of lipid profiles.

The most commonly reported side effects noted with maraviroc in the registrational trials were headache, dizziness, diarrhea, fatigue, upper respiratory tract infection, cough, abdominal pain, nasopharyngitis, rash, and bronchitis. In the MERIT study, diarrhea, vomiting, dizziness, abnormal dreams, cough and rash were more common in the efavirenz arm while bronchitis and nasopharyngitis were more common in the maraviroc arm. Although postural hypotension was noted with high doses of maraviroc early in its development, it was not seen at significantly different rates than the comparator arms in the Phase II/III trials (5\% MVC vs. $4 \%$ placebo). Similarly, clinically significant QT prolongation was not noted in the Phase IIb/III trials. As noted above the overall rate of adverse events leading to treatment discontinuation were low in all of these studies reinforcing the favorable tolerability profile of this drug.

\section{Trends in usage, 2010}

\section{Metabolic and cardiovascular benefits}

Untreated HIV infection leads to significant cardiovascular morbidity and mortality, and new data has led to recommendations for earlier antiretroviral treatment [110]. As HIV-infected patients live longer and take antiretrovirals for many years, metabolic effects from these agents are of greater concern. A number of agents have been implicated, although the data has been conflicting for agents such as abacavir [111-113]. Antiretroviral agents with more favorable metabolic profiles are clearly needed.

In treatment experienced patients who have a higher rate of cardiovascular disease at baseline, the rate of cardiovascular events seen with maraviroc treated patients was comparable to that reported in cohort studies of treatment experienced HIV patients, though it was higher than in the placebo arms [96]. All of the patients who had cardiac events in the trials had several

Table 2 Malignancies in Clinical Trials of Maraviroc

\begin{tabular}{|c|c|c|c|c|c|c|c|c|}
\hline \multirow{3}{*}{ Malignancy } & \multicolumn{6}{|c|}{ ART Experienced } & \multirow{2}{*}{\multicolumn{2}{|c|}{$\begin{array}{c}\text { ART Naive } \\
\text { MERIT }\end{array}$}} \\
\hline & & OTIVATE & & & n-R5 MVC & & & \\
\hline & MVC QD & MVC BID & OBR & MVC QD & MVC BID & OBR & MVC & EFV \\
\hline Lymphoma & 2 & 2 & 2 & 0 & 0 & 0 & 1 & 3 \\
\hline Kaposi Sarcoma & 1 & 2 & 3 & 0 & 0 & 0 & 0 & 1 \\
\hline Other & 0 & 0 & 0 & 1 & 1 & 1 & 2 & 3 \\
\hline
\end{tabular}


pre-existing risk factors for cardiovascular disease including diabetes, hypertension, previous myocardial infarction, known coronary artery disease, hyperlipidemia, and smoking. Treatment-naïve patients treated with maraviroc demonstrated a favorable lipid profile and decreased cardiovascular risk when compared to efavirenz. In the context of aging HIV-infected patients, the relatively neutral metabolic profile of maraviroc to date may prove useful in sparing future toxicities with their associated morbidity and mortality.

Patients initiating antiretroviral treatment who have pre-existing metabolic abnormalities may be candidates for use of a CCR5 antagonist such as maraviroc. However, in patients who are virally suppressed but experiencing metabolic complications on their current regimen, tropism testing cannot be done with the currently available phenotypic assay. Other genotypic assays or assays that can be performed on stored specimens are under study but are not currently available. This leaves the clinician in this situation with three options: 1) avoiding the switch to maraviroc due to lack of the tropism test, 2) testing for tropism at baseline prior to initiation of antiretroviral therapy, or 3) using maraviroc without tropism testing. The use of tropism testing prior to initiation of HAART is appealing and may turn out to have some prognostic value but is limited currently by the cost of the assay. If maraviroc is used without testing, it would be reasonable to check a viral load shortly (4-8 weeks) after switching therapy to ensure that viral suppression is maintained.

Development of newer CCR5 antagonists may also have a role in cardiovascular disease. One recent report demonstrated a new CCR5 antagonist that also has CCR2 blocking activity [22]. As CCR2 has been implicated in atherosclerosis, this could prove to be beneficial [114].

\section{Tuberculosis}

Management of the HIV-infected patient with tuberculosis is challenging due to drug-drug interactions between rifampin and antiretrovirals with similar metabolism through the hepatic cytochrome P450 system. This situation is more difficult in the setting of treatment experienced patients with limited treatment options. Although maraviroc is a substrate for CYP3A4, it can be dosed with rifampin by doubling the dose of maraviroc to $600 \mathrm{mg}$ twice daily [65].

\section{Hepatitis B and C coinfection}

Maraviroc did not appear to have a significant influence on the incidence of hepatic adverse events in patients coinfected with hepatitis B or C, though this assessment was based on very small numbers of coinfected patients [77]. Though maraviroc has proved safe to date in the small number of coinfected patients treated, CCR5 antagonism may have potential implications for the modulation of hepatitis $\mathrm{B}$ and $\mathrm{C}$ infections, independent of its effect on HIV. CCR5 has been implicated in the recruitment of $\mathrm{T}$ cells to the liver in chronic viral hepatitis leading to increases in inflammation [115]. One study in 283 women with hepatitis C suggested less severe hepatic inflammatory scores in individuals heterozygous for CCR5 $\Delta 32$ [116]. However, an analysis of 14 studies could find no association between susceptibility to hepatitis $C$ and CCR $5 \Delta 32$, but the lack of consistency between studies prevented an evaluation of the impact on liver fibrosis [117]. In contrast, the absence of CCR5 has been associated with recovery from hepatitis B $[118,119]$. Administration of anti-CCR5 monoclonal antibodies has decreased liver inflammation in a mouse model of liver failure [120]. Although these studies suggest that CCR5 antagonists could play a therapeutic role in hepatitis B, the studies in hepatitis $C$ have been conflicting and require further investigation $[116,121,122]$.

\section{Potential uses}

\section{Transmission}

Critical to acquisition of HIV is the chemokine receptor CCR5. The lack of surface expression of CCR5 (homozygosity for CCR5 $\triangle 32$ ) is protective against HIV acquisition, and individuals with heterozygous expression of CCR5 have a reduced rate of disease progression [13-15,123]. R5-tropic viruses are almost always the predominant strain in newly infected individuals in both adults and children [124,125], and this data suggests that drugs that block the CCR5 receptor might be particularly effective in the prevention of transmission.

Animal model studies have targeted the CCR5 receptor for prevention of transmission. Analogs of RANTES, a natural ligand of CCR5, have been evaluated as a microbicide and prevented vaginal SHIV transmission in Rhesus macaques [126-128]. Protection against a vaginal SHIV challenge was also provided by vaginally delivered fusion inhibitors and CCR5 antagonists $[129,130]$. Finally, oral CCR5 antagonists have protected against vaginal SHIV challenge in macaques [131]. These studies demonstrate the feasibility of developing microbicide candidates with CCR5 antagonists, but the challenges of developing a practical and effective formulation/delivery system for humans remain [132]. Further investigation is ongoing with a recent report of incorporating two antiretroviral agents, including maraviroc, into an elastomer vaginal ring [133].

For the reasons noted above, maraviroc seems particularly well suited to be incorporated as a component of regimens for post-exposure (occupational or non-occupational) or pre-exposure prophylaxis, especially because maraviroc attains good levels in both female and male 
genital secretions and in male rectal tissue $[67,70,134]$. Trials to evaluate maraviroc as part of PEP are planned [135]. There has been only one reported case of maraviroc as part of occupational PEP, a medical student stuck with a needle from a heavily treatment experienced HIV-infected man [136]. Although it is pregnancy category $\mathrm{B}$, there is no published experience with maraviroc in the prevention of mother to child transmission, but its characteristics merit consideration for preventing vertical transmission [65].

\section{Intensification}

The maraviroc arms in the MOTIVATE trials [75], the non-R5 tropism trial [78], and the MERIT trial [63] all demonstrated CD4 increases significantly greater than the comparator arms. A meta-analysis of clinical trials using CCR5 antagonists also found a significantly greater CD4 increase in CCR5 antagonist arms compared to regimens without one [137]. This finding led to adding maraviroc in virally suppressed patients who have inadequately reconstituted CD4 counts. A number of very small studies have evaluated this question, but none have demonstrated significant increases in CD4 counts [138-140]. Of interest, one of these studies [138] as well as others $[141,142]$ have reported downregulation in immune activation, a finding consistent with data from hepatitis $B$ and $C$ infections and graft versus host disease. This possibility suggests potential benefit beyond the antiviral effects of CCR5 antagonists.

\section{Organ transplantation}

Due to the role of CCR5 receptors in cell recruitment, migration and activation and the finding of lower rejection rates in renal transplant recipients homozygous for CCR $5 \Delta 32$, there has been an interest in modulation of CCR5 in the organ transplant setting [143]. Studies have evaluated both acute and chronic rejection in cardiac allograft transplantation in mice. Several studies evaluated mice that received cardiac allograft transplantation and cyclosporine and demonstrated that the mice that were CCR5 deficient or treated with a CCR5 antibody had prolonged allograft survival [144-146]. Prolonged allograft survival and decreased mononuclear infiltrate in the graft were also seen in mice treated with an antiCCR5 antibody and Rapamycin [147]. When the CCR5 antagonist, TAK-779, was administered to mice receiving cardiac transplants, reductions in the severity of intimal lesions and the number of graft infiltrating lymphocytes and attenuation of alloantigen-specific T-lymphocyte proliferation and IFN- $\gamma$ production were seen [148]. Another study used TAK-779 in both a murine cardiac and islet cell transplant model and found that treatment resulted in decreased chemokine, cytokine and chemokine receptor expression, prevented recruitment of lymphocytes into the allografts, and attenuated the development of chronic vasculopathy [149]. Similarly, in the cynomolgus monkey cardiac allograft model, diminished activity and recruitment of CCR5bearing leukocytes into the graft were attenuated by use of a CCR5 antagonist, though graft survival was only marginally prolonged [150].

In allogeneic bone marrow transplantation, CCR5 has been noted to be a marker for and has been implicated in the pathogenesis of graft versus host disease (GVHD) [151]. The absence of CCR5 has been associated with a lower risk of GVHD [152]. Use of an anti-CCR5 antibody has been shown to reduce GVHD-associated liver injury in a mouse model of GVHD [120]. These studies suggest that CCR5 antagonists may have a role in prolonging graft survival in solid organ and bone marrow transplantation and merit further investigation.

\section{Other considerations}

The CCR5 coreceptor modulates migration and activation of cells expressing the receptor, and so it may play a role in infections other than HIV.

\section{West Nile Virus (WNV)}

In mice WNV infection upregulated CCR5 and its ligand CCL5, which was associated with infiltration of CD4 and CD8 cells into the central nervous system (CNS); additionally, WNV infection in the absence of CCR5 was uniformly fatal [153]. A retrospective study in human cohorts revealed an association between CCR5 deficiency and symptomatic WNV disease, including death $[154,155]$. However, this association was not seen with heterozygous CCR $5 \Delta 32$. A more recent study in U.S. blood donors concluded that CCR5 deficiency was not by itself a risk factor for WNV acquisition but was associated with clinical symptoms of disease [156]. The clinical implications of these findings for patients treated with CCR5 antagonists are not yet known. Since a CCR5 antagonist is unlikely to block all CCR5 receptors in the body, treated patients may respond to WNV infection in a manner similar to individuals with heterozygous CCR $5 \Delta 32$. Further data from cohort studies and clinical trials are needed before the impact of CCR5 antagonists on WNV infection will be fully elucidated.

\section{Tick-borne Encephalitis (TBE)}

Like WNV, TBE virus is a flavivirus that can be associated with severe CNS disease. The findings with WNV led to evaluations of the role of CCR5 in a small cohort of Lithuanian patients. TBE was more frequent in CCR $5 \Delta 32$ homozygotes and the allele prevalence was higher among TBE patients than TBE-naïve patients with aseptic meningoencephalitis [157]. Further studies 
in larger populations and in populations treated with CCR5 antagonists are needed to confirm this association and determine the potential impact of treatment with CCR5 antagonists on flavivirus and other infections.

\section{Future directions}

The future roles for CCR5 antagonists in both the prevention and treatment of HIV infection are likely to expand. Recent data demonstrate the importance of CCR5 receptor density for HIV infection [158]. The density of CCR 5 defines both the infectability of target PBMC as well as the kinetics of HIV replication in infected cells. Human CD8-depleted PBMC were not able to sustain HIV infection if CCR5 receptor density was less than 2,300 molecules per cell [158]. Physiological levels of CCR 5 range between 2,000 molecules to 10,000 molecules per cell and can vary based on the state of immune activation.

HIV entry inhibitors' potency is directly impacted by the level of CCR5 expression. These include CCR5 antagonists, human antibodies that block viral entry, and fusion inhibitors. Mild differences in CCR5 density are associated with significant differences in IC50 and IC90 of each inhibitor [158-160]. These observations would suggest that as the degree of immune activation increases with progressive HIV-induced immune dysregulation, the in vivo potency of the entry inhibitor would be altered. In addition, these data suggest that therapy targeting immune activation may decrease CCR5 density, and thereby enhance the antiviral potency of entry inhibitors.

Our group has recently demonstrated that agents that block the progression of cell cycle at the G1- S interphase, are associated with downregulation of CCR5 expression. This decrease in CCR5 density is associated with an increase in potency of both CCR 5 antagonists and HIV fusion inhibitors [160-162]. This enhancement of antiviral activity was to the degree that CCR5-resistant isolates demonstrated IC50's and IC90's of wild type isolates when tested in combination with G1 cell cycle agents, or on cells with low level of CCR 5 expression [159]. Although speculative, the clinical implication of these findings is that the potency of CCR 5 antagonists can be significantly enhanced if used in combination with an agent that causes down-regulation of CCR5.

Current clinical development of CCR 5 agents has been approached as if these agents were just an additional antiviral drug to a growing number of effective anti-HIV drugs; but in reality these drugs represent an entire new paradigm in HIV therapeutics. Rather than acting on HIV viral targets, CCR5 agents directly target a distinct host cell pathway, and as such the "rules" are undoubtedly different than those established for agents that target HIV viral enzymes and HIV fusion proteins. For example, when a non-nucleoside reverse transcriptase inhibitor binds reverse transcriptase, it inhibits that molecule alone, yet when a CCR5 inhibitor binds CCR5 it first alters the density available for effective viral binding. Second it signals a down regulation of the cell's CCR5 molecules giving an effect that lasts for days. As such, there is a significant dichotomy between drug levels and drug effect. Another example would be the difference in resistance threshold. Host targets are much less likely to alter themselves for the benefit of the pathogen's survival, in distinction from the tendency of viral targets to mutate to escape immune pressure or drug effect. These features alone should alter what we define as the future "rules" for the clinical use of CCR 5 agents.

Over the past 25 years significant progress has been made in HIV therapeutics. Over the next 25 years, more advancement will certainly come. One area poised for immediate progress is the broad application of HIV antiretroviral therapy as the centerpiece of $21^{\text {st }}$ century HIV prevention efforts. Fundamental to all transmissible infectious diseases is that the infectivity of those infected drives the epidemic. In addition, application of the knowledge of how a pathogen completes its transmission cycle is crucial. HIV is mainly transmitted across mucous membranes via the transmitting virus R5 tropic stains which enter the new host via CCR5 receptors as long as CCR5 density is adequate. As such, it is clear that CCR5 antagonists will play a major role in the biological prevention of HIV transmission and acquisition. It is anticipated that clinical development pathways will carefully evaluate the role of CCR 5 antagonists in the transmission of HIV among discordant couples, both when included as a component of the antiviral therapy of the index case, as well as its role as a chemoprophylactic drug for high risk non-HIV infected partners. Also, of importance is the role CCR5 agents may play in blocking re-infection among individuals who are infected, but at risk for re-infection. The future role of agents for targeting CCR5 is urgently waiting to be fully defined and will require years of focused clinical investigation; yet this first class targeting host cell pathways is poised to herald a new wave in HIV therapeutic and biological HIV prevention.

\section{Acknowledgements}

This article has been published as part of Journal of Translational Medicine Volume 9 Supplement 1, 2011: Differential use of CCR5 vs. CSCR4 by HIV-1. Pathogenic, Translational and Clinical Open Questions. The full contents of the supplement are available online at http://www.translational-medicine. com/supplements/9/S1.

\section{Authors' contributions}

All authors conceived of the manuscript, and participated in its design and coordination. All authors made intellectual contributions and participated in the acquisition, analysis and interpretation of literature data, have been involved in drafting the manuscript, and approved the final manuscript. 


\section{Competing interests}

BLG, DJR, RRR have no competing interests.

Published: 27 January 2011

\section{References}

1. Dalgleish AG, Beverley PC, Clapham PR, Crawford DH, Greaves MF, Weiss RA: The CD4 (T4) antigen is an essential component of the receptor for the AIDS retrovirus. Nature 1984, 312:763-7.

2. Alkhatib G, Combadiere C, Broder CC, et al: CC CKR5: a RANTES, MIP1alpha, MIP-1 beta receptor as a fusion cofactor for macrophage-tropic HIV-1. Science 1996, 272:1955-8.

3. Dragic T, Litwin V, Allaway GP, et al: HIV-1 entry into CD4+ cells is mediated by the chemokine receptor CC-CKR-5. Nature 1996, 381:667-73.

4. Deng H, Liu R, Ellmeier W, et al: Identification of a major co-receptor for primary isolates of HIV-1. Nature 1996, 381:661-6.

5. Choe $H$, Farzan $M$, Sun $Y$, et al: The beta-chemokine receptors CCR3 and CCR5 facilitate infection by primary HIV-1 isolates. Cell 1996, 85:1135-48.

6. Oberlin E, Amara A, Bachelerie F, et al: The CXC chemokine SDF-1 is the ligand for LESTR/fusin and prevents infection by T-cell-line-adapted HIV1. Nature 1996, 382:833-5.

7. Doranz BJ, Rucker J, Yi Y, et al: A dual-tropic primary HIV-1 isolate that uses fusin and the beta-chemokine receptors CKR-5, CKR-3, and CKR-2b as fusion cofactors. Cell 1996, 85:1149-58.

8. Bleul CC, Farzan M, Choe H, et al: The lymphocyte chemoattractant SDF-1 is a ligand for LESTR/fusin and blocks HIV-1 entry. Nature 1996, 382:829-33.

9. Lapham CK, Ouyang J, Chandrasekhar B, Nguyen NY, Dimitrov DS, Golding $\mathrm{H}$ : Evidence for cell-surface association between fusin and the CD4-gp120 complex in human cell lines. Science 1996, 274:602-5.

10. Cocchi F, DeVico AL, Garzino-Demo A, Arya SK, Gallo RC, Lusso P: Identification of RANTES, MIP-1 alpha, and MIP-1 beta as the major HIVsuppressive factors produced by CD8+ T cells. Science 1995, 270:1811-5.

11. Lee B, Sharron M, Montaner $L$, Weissman D, Doms RW: Quantification of CD4, CCR5, and CXCR4 levels on lymphocyte subsets, dendritic cells, and differentially conditioned monocyte-derived macrophages. Proc Natl Acad Sci U S A 1999, 96:5215-20.

12. Michael NL, Chang G, Louie LG, et al: The role of viral phenotype and CCR-5 gene defects in HIV-1 transmission and disease progression. Nat Med 1997, 3:338-40.

13. Samson M, Libert F, Doranz BJ, et al: Resistance to HIV-1 infection in caucasian individuals bearing mutant alleles of the CCR- 5 chemokine receptor gene. Nature 1996, 382:722-5.

14. Liu R, Paxton WA, Choe S, et al: Homozygous defect in HIV-1 coreceptor accounts for resistance of some multiply-exposed individuals to HIV-1 infection. Cell 1996, 86:367-77.

15. Huang Y, Paxton WA, Wolinsky SM, et al: The role of a mutant CCR5 allele in HIV-1 transmission and disease progression. Nat Med 1996, 2:1240-3.

16. de Roda Husman AM, Koot M, Cornelissen M, et al: Association between CCR5 genotype and the clinical course of HIV-1 infection. Ann Intern Med 1997, 127:882-90.

17. Nichols WG, Steel HM, Bonny T, et al: Hepatotoxicity observed in clinical trials of aplaviroc (GW873140). Antimicrob Agents Chemother 2008, 52:858-65.

18. Cohen C, Dejesus E, Mills A, et al: Potent antiretroviral activity of the once-daily CCR5 antagonist INCB009471 over 14 days of monotherapy [Abstract TUAB106]. In: 4th IAS Conference on HIV Pathogenesis, Treatment and Prevention 2007, Sydney, Australia.

19. Shin N, Solomon K, Wang KH, et al: INCB9471 is a non-competitive small molecule antagonist of CCR5 [Abstract $\mathrm{H}-1032]$. In: 47th Interscience Conference on Antimicrobial Agents and Chemotherapy 2007, Chicago, IL.

20. Solomon K, Baribaud F, Shin N, et al: INCB9471 is a potent inhibitor of R5HIV-1 infection in vitro [Abstract H-1033]. In: 47th Interscience Conference on Antimicrobial Agents and Chemotherapy 2007, Chicago, IL.

21. Martin D, Palleja S, Pheng L, Trinh M, Marier J-F, Sapirstein J: Pharmacokinetics and pharmacodynamics of TBR 652, a chemokine receptor 5 antagonist, in HIV-1-infected, ART-experienced, CCR5 antagonist-naïve patients [Abstract 598]. In: 17th Conference on Retroviruses and Opportunistic Infections 2010, San Francisco, CA.

22. Palleja S, Cohen C, Gathe J, et al: Safety and efficacy of TBR 652, a CCR5 antagonist, in HIV-1-infected, ART-experienced, CCR5 antagonist-naïve patients [Abstract 53]. In: 17th Conference on Retroviruses and Opportunistic Infections 2010, San Francisco, CA.

23. Jacobson JM, Saag MS, Thompson MA, et al: Antiviral activity of singledose PRO 140, a CCR5 monoclonal antibody, in HIV-infected adults. $J$ Infect Dis 2008, 198:1345-52.

24. Lalezari J, Yadavalli GK, Para M, et al: Safety, pharmacokinetics, and antiviral activity of $\mathrm{HGS004}$, a novel fully human IgG4 monoclonal antibody against CCR5, in HIV-1-infected patients. J Infect Dis 2008, 197:721-7.

25. Latinovic O, Kuruppu J, Davis C, Le N, Heredia A: Pharmacotherapy of HIV1 infection: focus on CCR5 antagonist maraviroc. Clin Med Ther 2009, 1:1497-510.

26. Lieberman-Blum SS, Fung HB, Bandres JC: Maraviroc: a CCR5-receptor antagonist for the treatment of HIV-1 infection. Clin Ther 2008, 30:1228-50.

27. Dragic T, Trkola A, Thompson DA, et al: A binding pocket for a small molecule inhibitor of HIV-1 entry within the transmembrane helices of CCR5. Proc Natl Acad Sci U S A 2000, 97:5639-44.

28. Maeda K, Das D, Ogata-Aoki $H$, et al: Structural and molecular interactions of CCR5 inhibitors with CCR5. J Biol Chem 2006, 281:12688-98.

29. Seibert C, Ying W, Gavrilov S, et al: Interaction of small molecule inhibitors of HIV-1 entry with CCR5. Virology 2006, 349:41-54.

30. Kondru R, Zhang J, Ji C, et al: Molecular interactions of CCR5 with major classes of small-molecule anti-HIV CCR5 antagonists. Mol Pharmacol 2008, 73:789-800.

31. Olson WC, Rabut GE, Nagashima KA, et al: Differential inhibition of human immunodeficiency virus type 1 fusion, gp120 binding, and CCchemokine activity by monoclonal antibodies to CCR5. J Virol 1999, 73:4145-55.

32. Castagna A, Biswas P, Beretta A, Lazzarin A: The appealing story of HIV entry inhibitors : from discovery of biological mechanisms to drug development. Drugs 2005, 65:879-904.

33. Cormier EG, Dragic T: The crown and stem of the V3 loop play distinct roles in human immunodeficiency virus type 1 envelope glycoprotein interactions with the CCR5 coreceptor. J Virol 2002, 76:8953-7.

34. Berger EA, Doms RW, Fenyo EM, et al: A new classification for HIV-1. Nature 1998, 391:240.

35. Bartlett J, Gallant J, Pham P: Medical management of HIV infection. Durham, NC: Knowledge Source Solutions, LLC; 2009.

36. Tersmette M, de Goede RE, Al BJ, et al: Differential syncytium-inducing capacity of human immunodeficiency virus isolates: frequent detection of syncytium-inducing isolates in patients with acquired immunodeficiency syndrome (AIDS) and AIDS-related complex. J Virol 1988, 62:2026-32.

37. Tersmette M, Lange JM, de Goede RE, et al: Association between biological properties of human immunodeficiency virus variants and risk for AIDS and AIDS mortality. Lancet 1989, 1:983-5.

38. Koot M, Keet IP, Vos AH, et al: Prognostic value of HIV-1 syncytiuminducing phenotype for rate of CD4+ cell depletion and progression to AIDS. Ann Intern Med 1993, 118:681-8.

39. Bjorndal $A$, Deng $H$, Jansson $M$, et al: Coreceptor usage of primary human immunodeficiency virus type 1 isolates varies according to biological phenotype. J Virol 1997, 71:7478-87.

40. Connor Rl, Sheridan KE, Ceradini D, Choe S, Landau NR: Change in coreceptor use correlates with disease progression in HIV-1-infected individuals. J Exp Med 1997, 185:621-8.

41. Pope M, Haase AT: Transmission, acute HIV-1 infection and the quest for strategies to prevent infection. Nat Med 2003, 9:847-52.

42. Brumme ZL, Goodrich J, Mayer HB, et al: Molecular and clinical epidemiology of CXCR4-using HIV-1 in a large population of antiretroviral-naive individuals. J Infect Dis 2005, 192:466-74.

43. Shen R, Richter HE, Clements RH, et al: Macrophages in vaginal but not intestinal mucosa are monocyte-like and permissive to human immunodeficiency virus type 1 infection. J Virol 2009, 83:3258-67.

44. Kuritzkes DR: HIV-1 entry inhibitors: an overview. Curr Opin HIV AIDS 2009, 4:82-7.

45. Moyle GJ, Wildfire A, Mandalia S, et al: Epidemiology and predictive factors for chemokine receptor use in HIV-1 infection. J Infect Dis 2005, 191:866-72.

46. Waters L, Mandalia S, Randell P, Wildfire A, Gazzard B, Moyle G: The impact of HIV tropism on decreases in CD4 cell count, clinical progression, and 
subsequent response to a first antiretroviral therapy regimen. Clin Infect Dis 2008, 46:1617-23.

47. Hughes A, Nelson M: HIV entry: new insights and implications for patient management. Curr Opin Infect Dis 2009, 22:35-42.

48. Cilliers T, Nhlapo J, Coetzer M, et al: The CCR5 and CXCR4 coreceptors are both used by human immunodeficiency virus type 1 primary isolates from subtype C. J Virol 2003, 77:4449-56.

49. Mueller MC, Bogner JR: Treatment with CCR5 antagonists: which patient may have a benefit? Eur J Med Res 2007, 12:441-52.

50. Hoffmann C: The epidemiology of HIV coreceptor tropism. Eur J Med Res 2007, 12:385-90

51. Patel MB, Hoffman NG, Swanstrom R: Subtype-specific conformational differences within the $\mathrm{V} 3$ region of subtype $B$ and subtype $C$ human immunodeficiency virus type 1 Env proteins. J Virol 2008, 82:903-16.

52. Kaleebu $\mathrm{P}$, Nankya IL, Yirrell $\mathrm{DL}$, et al: Relation between chemokine receptor use, disease stage, and HIV-1 subtypes $A$ and D: results from a rural Ugandan cohort. J Acquir Immune Defic Syndr 2007, 45:28-33.

53. Begaud $E$, Feindirongai $G$, Versmisse $P$, et al: Broad spectrum of coreceptor usage and rapid disease progression in HIV-1-infected individuals from Central African Republic. AIDS Res Hum Retroviruses 2003, 19:551-60.

54. Tscherning C, Alaeus A, Fredriksson R, et al: Differences in chemokine coreceptor usage between genetic subtypes of HIV-1. Virology 1998, 241:181-8.

55. Huang W, Eshleman SH, Toma J, et al: Coreceptor tropism in human immunodeficiency virus type 1 subtype D: high prevalence of CXCR4 tropism and heterogeneous composition of viral populations. J Virol 2007, 81:7885-93.

56. Menu E, Reynes JM, Muller-Trutwin MC, et al: Predominance of CCR5dependent HIV-1 subtype E isolates in Cambodia. J Acquir Immune Defic Syndr Hum Retrovirol 1999, 20:481-7.

57. Subbarao S, Vanichseni S, Hu DJ, et al: Genetic characterization of incident HIV type 1 subtype $E$ and $B$ strains from a prospective cohort of injecting drug users in Bangkok, Thailand. AIDS Res Hum Retroviruses 2000, 16:699-707.

58. Soriano $V$, Perno CF, Kaiser $R$, et al: When and how to use maraviroc in HIV-infected patients. AIDS 2009, 23:2377-85.

59. Poveda E, Briz V, Quinones-Mateu M, Soriano V: HIV tropism: diagnostic tools and implications for disease progression and treatment with entry inhibitors. AIDS 2006, 20:1359-67.

60. MacArthur RD, Novak RM: Maraviroc: the first of a new class of antiretroviral agents. Clin Infect Dis 2008, 47:236-41.

61. Whitcomb JM, Huang W, Fransen S, et al: Development and characterization of a novel single-cycle recombinant-virus assay to determine human immunodeficiency virus type 1 coreceptor tropism. Antimicrob Agents Chemother 2007, 51:566-75.

62. Su Z, Gulick RM, Krambrink A, et al: Response to vicriviroc in treatmentexperienced subjects, as determined by an enhanced-sensitivity coreceptor tropism assay: reanalysis of AIDS clinical trials group A5211. J Infect Dis 2009, 200:1724-8.

63. Cooper DA, Heera J, Goodrich J, et al: Maraviroc versus efavirenz, both in combination with zidovudine-lamivudine, for the treatment of antiretroviral-naive subjects with CCR5-tropic HIV-1 infection. J Infect Dis 2010, 201:803-13.

64. Abel S, Russell D, Whitlock LA, Ridgway CE, Nedderman AN, Walker DK: Assessment of the absorption, metabolism and absolute bioavailability of maraviroc in healthy male subjects. Br J Clin Pharmacol 2008, 65(Suppl 1):60-7.

65. Pfizer Inc: Selzentry [package insert]. 2007, New York.

66. Walker DK, Bowers SJ, Mitchell RJ, Potchoiba MJ, Schroeder CM, Small HF: Preclinical assessment of the distribution of maraviroc to potential human immunodeficiency virus (HIV) sanctuary sites in the central nervous system (CNS) and gut-associated lymphoid tissue (GALT). Xenobiotica 2008, 38:1330-9.

67. Tiraboschi JM, Curto J, Niubo JDP: Maraviroc levels in cerebrospinal fluid and seminal plasma from HIV-infected patients [Abstract 612]. In: 17th Conference on Retroviruses and Opportunistic Infections 2010, San Francisco, CA.

68. Melica G, Canestri A, Peytavin G, et al: Maraviroc-containing regimen suppresses HIV replication in the cerebrospinal fluid of patients with neurological symptoms. AIDS 2010, 24(13):2130-2133.
69. Yilmaz A, Watson V, Else L, Gisslen M: Cerebrospinal fluid maraviroc concentrations in HIV-1 infected patients. AIDS 2009, 23:2537-40.

70. Dumond JB, Patterson KB, Pecha AL, et al: Maraviroc concentrates in the cervicovaginal fluid and vaginal tissue of HIV-negative women. J Acquir Immune Defic Syndr 2009, 51:546-53.

71. Abel S, Russell D, Taylor-Worth RJ, Ridgway CE, Muirhead GJ: Effects of CYP3A4 inhibitors on the pharmacokinetics of maraviroc in healthy volunteers. Br J Clin Pharmacol 2008, 65(Suppl 1):27-37.

72. Abel $S$, Jenkins $T M$, Whitlock $L A$, Ridgway $C E$, Muirhead GJ: Effects of CYP3A4 inducers with and without CYP3A4 inhibitors on the pharmacokinetics of maraviroc in healthy volunteers. Br I Clin Pharmacol 2008, 65(Suppl 1):38-46.

73. Abel S, Davis JD, Ridgway CE, Hamlin JC, Vourvahis M: Pharmacokinetics, safety and tolerability of a single oral dose of maraviroc in HIV-negative subjects with mild and moderate hepatic impairment. Antivir Ther 2009, 14:831-7.

74. Fatkenheuer G, Pozniak AL, Johnson MA, et al: Efficacy of short-term monotherapy with maraviroc, a new CCR5 antagonist, in patients infected with HIV-1. Nat Med 2005, 11:1170-2.

75. Gulick RM, Lalezari J, Goodrich J, et al: Maraviroc for previously treated patients with R5 HIV-1 infection. N Engl J Med 2008, 359:1429-41.

76. Asmuth DM, Goodrich J, Cooper DA, et al: CD4+ T-cell restoration after 48 weeks in the maraviroc treatment-experienced trials MOTIVATE 1 and 2. J Acquir Immune Defic Syndr 2009

77. Fatkenheuer G, Nelson M, Lazzarin A, et al: Subgroup analyses of maraviroc in previously treated R5 HIV-1 infection. N Engl J Med 2008, 359:1442-55.

78. Saag M, Goodrich J, Fatkenheuer G, et al: A double-blind, placebocontrolled trial of maraviroc in treatment-experienced patients infected with non-R5 HIV-1. J Infect Dis 2009, 199:1638-47.

79. Nozza S, Galli L, Visco F, et al: Raltegravir, maraviroc, etravirine: an effective protease inhibitor and nucleoside reverse transcriptase inhibitor-sparing regimen for salvage therapy in HIV-infected patients with triple-class experience. AIDS 2010, 24:924-8.

80. Armstrong-James D, Stebbing J, Scourfield A, et al: Clinical outcome in resistant HIV-2 infection treated with raltegravir and maraviroc. Antiviral Res 2010, 86:224-6.

81. Baba M, Miyake H, Wang X, Okamoto M, Takashima K: Isolation and characterization of human immunodeficiency virus type 1 resistant to the small-molecule CCR5 antagonist TAK-652. Antimicrob Agents Chemother 2007, 51:707-15.

82. Ogert RA, Wojcik L, Buontempo C, et al: Mapping resistance to the CCR5 co-receptor antagonist vicriviroc using heterologous chimeric HIV-1 envelope genes reveals key determinants in the C2-V5 domain of gp120. Virology 2008, 373:387-99.

83. Anastassopoulou CG, Ketas TJ, Klasse PJ, Moore JP: Resistance to CCR5 inhibitors caused by sequence changes in the fusion peptide of HIV-1 gp41. Proc Natl Acad Sci U S A 2009, 106:5318-23.

84. Westby M, Smith-Burchnell C, Mori J, et al: Reduced maximal inhibition in phenotypic susceptibility assays indicates that viral strains resistant to the CCR5 antagonist maraviroc utilize inhibitor-bound receptor for entry. J Virol 2007, 81:2359-71.

85. Moore JP, Kuritzkes DR: A piece de resistance: how HIV-1 escapes small molecule CCR5 inhibitors. Curr Opin HIV AIDS 2009, 4:118-24.

86. Trkola A, Kuhmann SE, Strizki JM, et al: HIV-1 escape from a small molecule, CCR5-specific entry inhibitor does not involve CXCR4 use. Proc Natl Acad Sci U S A 2002, 99:395-400.

87. Pugach P, Marozsan AJ, Ketas TJ, Landes EL, Moore JP, Kuhmann SE: HIV-1 clones resistant to a small molecule CCR5 inhibitor use the inhibitorbound form of CCR5 for entry. Virology 2007, 361:212-28.

88. Pastore C, Ramos A, Mosier DE: Intrinsic obstacles to human immunodeficiency virus type 1 coreceptor switching. J Virol 2004, 78:7565-74.

89. Pastore C, Nedellec R, Ramos A, et al: Conserved changes in envelope function during human immunodeficiency virus type 1 coreceptor switching. J Virol 2007, 81:8165-79.

90. Gathe J, Diaz R, Fatkenheuer $G$, et al: Phase 3 trials of vicriviroc in treatment-experienced subjects demonstrate safety but not significantly superior efficacy over potent background regimens alone [Abstract 54LB]. In: 17th Conference on Retroviruses and Opportunistic Infections 2010, San Francisco, CA. 
91. Gulick RM, Su Z, Flexner C, et al: Phase 2 study of the safety and efficacy of vicriviroc, a CCR5 inhibitor, in HIV-1-Infected, treatment-experienced patients: AIDS clinical trials group 5211. J Infect Dis 2007, 196:304-12.

92. Suleiman J, Zingman BS, Diaz RS, et al: Vicriviroc in combination therapy with an optimized regimen for treatment-experienced subjects: 48-week results of the VICTOR-E1 phase 2 trial. J Infect Dis 2010, 201:590-9.

93. Landovitz RJ, Angel JB, Hoffmann C, et al: Phase II study of vicriviroc versus efavirenz (both with zidovudine/lamivudine) in treatment-naive subjects with HIV-1 infection. J Infect Dis 2008, 198:1113-22.

94. Tsibris AM, Korber B, Arnaout R, et al: Quantitative deep sequencing reveals dynamic HIV-1 escape and large population shifts during CCR5 antagonist therapy in vivo. PLoS One 2009, 4:e5683.

95. Westby $M$, Lewis M, Whitcomb J, et al: Emergence of CXCR4-using human immunodeficiency virus type 1 (HIV-1) variants in a minority of HIV-1infected patients following treatment with the CCR5 antagonist maraviroc is from a pretreatment CXCR4-using virus reservoir. I Virol 2006, 80:4909-20.

96. Pfizer Inc: Maraviroc Tablets NDA 22-128: Antiviral Drugs Advisory Committee (AVDAC) briefing document., April 24, 2007. Available at: http://www.fda.gov/ohrms/dockets/ac/07/briefing/2007-4283b1-01-Pfizer pdf. Accessed July 5, 2010.

97. Tsibris AM, Sagar M, Gulick RM, et al: In vivo emergence of vicriviroc resistance in a human immunodeficiency virus type 1 subtype Cinfected subject. J Virol 2008, 82:8210-4.

98. Tsibris A, Leopold K, Paredes R, et al: Reduced fitness of vicriviroc-resistant HIV-1 leads to rapid post-treatment reversion in vivo [Abstract 638]. In: 17th Conference on Retroviruses and Opportunistic Infections 2010, San Francisco, CA.

99. Anastassopoulou CG, Marozsan AJ, Matet A, et al: Escape of HIV-1 from a small molecule CCR5 inhibitor is not associated with a fitness loss. PLOS Pathog 2007, 3:e79.

100. Jubb B, Lewis M, Simpson P, et al: CCR5-tropic resistance to maraviroc is uncommon even among patients on functional maraviroc monotherapy or with ongoing low-level replication [Abstract 639]. In: 16th Conference on Retroviruses and Opportunistic Infections 2009, Montreal, Canada.

101. Craig C, Heera J, Lewis M, et al: Mechanisms of virologic failure with maraviroc in treatment-naïve HIV-1-infected patients through 96 weeks [Abstract 536]. In: 17th Conference on Retroviruses and Opportunistic Infections 2010, San Francisco, CA.

102. Lewis M, Mori J, Simpson P, et al: Changes in V3 loop sequence associated with failure of maraviroc treatment in patients enrolled in the MOTIVATE 1 and 2 trials [Abstract 871]. In: 15th Conference on Retroviruses and Opportunistic Infections 2008, Boston, MA.

103. Mori J, Mosley M, Lewis $M$, et al: Characterization of maraviroc resistance in patients failing treatment with CCR5-tropic HIV-1 in MOTIVATE 1 and 2 [Abstract 10]. In: XVI International HIV Drug Resistance Workshop 2007, Barbados, West Indies.

104. Saracino A, Monno L, Brindicci G, et al: Are the proposed env mutations actually associated with resistance to maraviroc? I Acquir Immune Defic Syndr 2010, 53:550-2

105. Soulie C, Malet I, Lambert-Niclot S, et al: Primary genotypic resistance of HIV-1 to CCR5 antagonists in CCR5 antagonist treatment-naive patients. AIDS 2008, 22:2212-4.

106. Pugach P, Ketas TJ, Michael E, Moore JP: Neutralizing antibody and antiretroviral drug sensitivities of HIV-1 isolates resistant to small molecule CCR5 inhibitors. Virology 2008, 377:401-7.

107. Tsibris AM, Paredes R, Chadburn A, et al: Lymphoma diagnosis and plasma Epstein-Barr virus load during vicriviroc therapy: results of the AIDS Clinical Trials Group A5211. Clin Infect Dis 2009, 48:642-9.

108. Hoepelman IM, Ayoub A, Heera J, et al: The incidence of severe liver enzyme abnormalities and hepatic adverse events in the maraviroc clinical development programme [Abstract LBP7.9/1]. In: 11th European AIDS Conference/EACS 2007, Madrid, Spain.

109. DeJesus E, Walmsley S, Cohen C, et al: Fasted lipid changes after administration of maraviroc or efavirenz in combination with zidovudine and lamivudine for 48 weeks to treatment-naïve HIV-infected patients [Abstract 929]. In: 15th Conference on Retroviruses and Opportunistic Infections 2008, Boston, MA.

110. Panel on Antiretroviral Guidelines for Adults and Adolescents: Guidelines for the use of antiretroviral agents in HIV-1-infected adults and adolescents., December 1, 2009. Available at: Available at http://www. aidsinfo.nih.gov/ContentFiles/AdultandAdolescentGL.pdf. Accessed June 11, 2010.

111. Friis-Moller N, Reiss $P$, Sabin CA, et al: Class of antiretroviral drugs and the risk of myocardial infarction. N Engl J Med 2007, 356:1723-35.

112. Sabin CA, Worm SW, Weber $R$, et al: Use of nucleoside reverse transcriptase inhibitors and risk of myocardial infarction in HIV-infected patients enrolled in the D:A:D study: a multi-cohort collaboration. Lancet 2008, 371:1417-26.

113. Bedimo R, Westfall A, Drechsler HPT: Abacavir use and risk of acute myocardial infarction and cerebrovascular disease in the HAART era [Abstract MOAB202]. In: 5th IAS Conference on HIV Pathogenesis, Treatment and Prevention 2009, Cape Town, South Africa.

114. Charo IF, Ransohoff RM: The many roles of chemokines and chemokine receptors in inflammation. N Engl J Med 2006, 354:610-21.

115. Larrubia JR, Benito-Martinez S, Calvino M, Sanz-de-Villalobos E, Parra-Cid T: Role of chemokines and their receptors in viral persistence and liver damage during chronic hepatitis C virus infection. World J Gastroenterol 2008, 14:7149-59.

116. Goulding C, MCManus R, Murphy A, et al: The CCR5-delta32 mutation: impact on disease outcome in individuals with hepatitis $C$ infection from a single source. Gut 2005, 54:1157-61.

117. Wheeler J, McHale M, Jackson V, Penny M: Assessing theoretical risk and benefit suggested by genetic association studies of CCR5: experience in a drug development programme for maraviroc. Antivir Ther 2007, 12:233-45.

118. Thio CL, Astemborski J, Bashirova A, et al: Genetic protection against hepatitis B virus conferred by CCR5Delta32: Evidence that CCR5 contributes to viral persistence. J Virol 2007, 81:441-5.

119. Thio $\mathrm{CL}$, Astemborski J, Thomas $\mathrm{R}$, et al: Interaction between RANTES promoter variant and CCR5Delta32 favors recovery from hepatitis B. J Immunol 2008, 181:7944-7.

120. Murai M, Yoneyama $H$, Harada A, et al: Active participation of CCR5(+)CD8 (+) T lymphocytes in the pathogenesis of liver injury in graft-versus-host disease. J Clin Invest 1999, 104:49-57.

121. Hellier S, Frodsham AJ, Hennig BJ, et al: Association of genetic variants of the chemokine receptor CCR5 and its ligands, RANTES and MCP-2, with outcome of HCV infection. Hepatology 2003, 38:1468-76.

122. Vincent $T$, Portales $P$, Baillat $V$, et al: T-Cell surface CCR5 density is not correlated with hepatitis severity in hepatitis $C$ virus/HIV-coinfected individuals: implications for the therapeutic use of CCR5 antagonists. $J$ Acquir Immune Defic Syndr 2005, 38:305-9.

123. Dean M, Carrington M, Winkler C, et al: Genetic restriction of HIV-1 infection and progression to AIDS by a deletion allele of the CKR5 structural gene. Hemophilia Growth and Development Study, Multicenter AIDS Cohort Study, Multicenter Hemophilia Cohort Study, San Francisco City Cohort, ALIVE Study. Science 1996, 273:1856-62.

124. Poles MA, Elliott J, Taing P, Anton PA, Chen IS: A preponderance of CCR5 (+) CXCR4(+) mononuclear cells enhances gastrointestinal mucosal susceptibility to human immunodeficiency virus type 1 infection. J Virol 2001, 75:8390-9.

125. van't Wout AB, Kootstra NA, Mulder-Kampinga GA, et al: Macrophagetropic variants initiate human immunodeficiency virus type 1 infection after sexual, parenteral, and vertical transmission. J Clin Invest 1994, 94:2060-7.

126. Lederman MM, Veazey RS, Offord R, et al: Prevention of vaginal SHIV transmission in rhesus macaques through inhibition of CCR5. Science 2004, 306:485-7.

127. Kish-Catalone TM, Lu W, Gallo RC, DeVico AL: Preclinical evaluation of synthetic -2 RANTES as a candidate vaginal microbicide to target CCR5. Antimicrob Agents Chemother 2006, 50:1497-509.

128. Veazey RS, Ling B, Green LC, et al: Topically applied recombinant chemokine analogues fully protect macaques from vaginal simianhuman immunodeficiency virus challenge. J Infect Dis 2009, 199:1525-7.

129. Veazey RS, Klasse PJ, Schader SM, et al: Protection of macaques from vaginal SHIV challenge by vaginally delivered inhibitors of virus-cell fusion. Nature 2005, 438:99-102.

130. Veazey RS, Ketas TA, Klasse PJ, et al: Tropism-independent protection of macaques against vaginal transmission of three SHIVs by the HIV-1 fusion inhibitor T-1249. Proc Natl Acad Sci U S A 2008, 105:10531-6. 
131. Veazey RS, Springer MS, Marx PA, Dufour J, Klasse PJ, Moore JP: Protection of macaques from vaginal SHIV challenge by an orally delivered CCR5 inhibitor. Nat Med 2005, 11:1293-4.

132. Ramjee G: Microbicide research: current and future directions. Curr Opin HIV AIDS 2010, 5:316-21.

133. Faheem A, McCoy C, McBride M, Malcolm K, Woolfson DMS: Simultaneous sustained release of maraviroc and dapivirine from silicone elastomer vaginal rings [Abstract 1069]. In: 16th Conference on Retroviruses and Opportunistic Infections 2009, Montreal, Canada.

134. Brown K, Patterson K, Malone S, et al: Antiretrovirals for prevention: maraviroc exposure in the semen and rectal tissue of healthy male volunteers after single and multiple dosing [Abstract 85]. In: 17th Conference on Retroviruses and Opportunistic Infections 2010, San Francisco, CA.

135. Barber TJ, Benn PD: Postexposure prophylaxis for HIV following sexual exposure. Curr Opin HIV AIDS 2010, 5:322-6.

136. Mechai F, Quertainmont Y, Sahali S, Delfraissy JF, Ghosn J: Post-exposure prophylaxis with a maraviroc-containing regimen after occupational exposure to a multi-resistant HIV-infected source person. J Med Virol 2008, 80:9-10.

137. Wilkin T, Ribaudo H, Gulick R: The relationship of CCR5 inhibitors to CD4 cell count changes: a meta-analysis of recent clinical trials in treatmentexperienced subjects [Abstract 800]. In: 15th Conference on Retroviruses and Opportunistic Infections 2008, Boston, MA.

138. Wilkin T, Lalama C, Tenorio A, et al: Maraviroc intensification for suboptimal CD4+ cell response despite sustained virologic suppression: ACTG 5256 [Abstract 285]. In: 17th Conference on Retroviruses and Opportunistic Infections 2010, San Francisco, CA.

139. Evering T, Mehandru S, Poles $M$, et al: Antiviral and immunological effects of intensification of suppressive ART with maraviroc, a CCR5 antagonist [Abstract 283]. In: 17th Conference on Retroviruses and Opportunistic Infections 2010, San Francisco, CA.

140. Eng RHK, Perez G, Paez SL, Chiang TS: SM S. Impact of adding maraviroc to HIV patients with undetectable plasma RNA but are non-CD4 progressors (CD4 200cell/mm3) [Abstract $\mathrm{H}-1247]$. In: 48th Annual ICAACl IDSA 46th Annual Meeting 2008, Washington, DC.

141. Sauzullo I, Lichtner M, Mengoni F, et al: Effect in vitro of CCR5 antagonists on innate immune system: maraviroc inhibits the migration of neutrophils, macrophages, and DC [Abstract 512]. In: 17th Conference on Retroviruses and Opportunistic Infections 2010, San Francisco, CA

142. Funderburg N, Kalinowska M, Eason J, et al: Differential effects of maraviroc (MVC) and efavirenz (EFV) on markers of immune activation (IA) and inflammation and their association with CD4 cell rises: a subanalysis of the MERIT study [Abstract $\mathrm{H}-1582]$. In: 49th Interscience Conference on Antimicrobial Agents and Chemotherapy 2009, Boston, MA.

143. Fischereder M, Luckow B, Hocher B, et al: CC chemokine receptor 5 and renal-transplant survival. Lancet 2001, 357:1758-61.

144. Gao W, Faia KL, Csizmadia V, et al: Beneficial effects of targeting CCR5 in allograft recipients. Transplantation 2001, 72:1199-205.

145. Jun $L$, Kailun $Z$, Aini $X$, et al: Combined treatment with chemokine receptor 5 blocker and cyclosporine induces prolonged graft survival in a mouse model of cardiac transplantation. J Heart Lung Transplant 2010, 29:461-70.

146. Li J, Xia J, Zhang K, Xu L: Suppression of acute and chronic cardiac allograft rejection in mice by inhibition of chemokine receptor 5 in combination with cyclosporine A. J Surg Res 2009, 157:81-90.

147. Li J, Zhang K, Ye P, Wang S, Xia J: CCR5 blockade in combination with rapamycin prolongs cardiac allograft survival in mice. Clin Exp Immunol 2009, 157:437-45.

148. Bastani S, Sherman W, Schnickel GT, et al: Chemokine receptor blockade with a synthetic nonpeptide compound attenuates cardiac allograft vasculopathy. Transplantation 2009, 88:995-1001.

149. Akashi S, Sho M, Kashizuka $\mathrm{H}$, et al: A novel small-molecule compound targeting CCR5 and CXCR3 prevents acute and chronic allograft rejection. Transplantation 2005, 80:378-84.

150. Schroder C, Pierson RN 3rd, Nguyen BN, et al: CCR5 blockade modulates inflammation and alloimmunity in primates. J Immunol 2007, 179:2289-99.

151. Palmer LA, Sale GE, Balogun Jl, et al: Chemokine receptor CCR5 mediates alloimmune responses in graft-versus-host disease. Biol Blood Marrow Transplant 2010, 16:311-9.
152. Bogunia-Kubik K, Duda D, Suchnicki K, Lange A: CCR5 deletion mutation and its association with the risk of developing acute graft-versus-host disease after allogeneic hematopoietic stem cell transplantation. Haematologica 2006, 91:1628-34.

153. Glass WG, Lim JK, Cholera R, Pletnev AG, Gao JL, Murphy PM: Chemokine receptor CCR5 promotes leukocyte trafficking to the brain and survival in West Nile virus infection. J Exp Med 2005, 202:1087-98.

154. Glass WG, McDermott DH, Lim JK, et al: CCR5 deficiency increases risk of symptomatic West Nile virus infection. J Exp Med 2006, 203:35-40.

155. Lim JK, Louie CY, Glaser C, et al: Genetic deficiency of chemokine receptor CCR5 is a strong risk factor for symptomatic West Nile virus infection: a meta-analysis of 4 cohorts in the US epidemic. J Infect Dis 2008, 197:262-5.

156. Lim JK, McDermott DH, Lisco A, et al: CCR5 deficiency is a risk factor for early clinical manifestations of West Nile virus infection but not for viral transmission. J Infect Dis 2010, 201:178-85.

157. Kindberg $E$, Mickiene $A, A x C$, et al: $A$ deletion in the chemokine receptor 5 (CCR5) gene is associated with tickborne encephalitis. J Infect Dis 2008, 197:266-9.

158. Heredia A, Gilliam B, DeVico A, et al: CCR5 density levels on primary CD4 T cells impact the replication and Enfuvirtide susceptibility of R5 HIV-1. AIDS 2007, 21:1317-22.

159. Heredia A, Latinovic O, Gallo RC, et al: Reduction of CCR5 with low-dose rapamycin enhances the antiviral activity of vicriviroc against both sensitive and drug-resistant HIV-1. Proc Natl Acad Sci U S A 2008, 105:20476-81.

160. Latinovic O, Heredia A, Gallo RC, Reitz M, Le N, Redfield RR: Rapamycin enhances aplaviroc anti-HIV activity: implications for the clinical development of novel CCR5 antagonists. Antiviral Res 2009, 83:86-9.

161. Heredia A, Amoroso A, Davis C, et al: Rapamycin causes down-regulation of CCR5 and accumulation of anti-HIV beta-chemokines: an approach to suppress R5 strains of HIV-1. Proc Natl Acad Sci U S A 2003, 100:10411-6.

162. Heredia A, Gilliam B, Latinovic O, et al: Rapamycin reduces CCR5 density levels on CD4 T cells, and this effect results in potentiation of enfuvirtide (T-20) against R5 strains of human immunodeficiency virus type 1 in vitro. Antimicrob Agents Chemother 2007, 51:2489-96.

doi:10.1186/1479-5876-9-S1-S9

Cite this article as: Gilliam et al: Clinical use of CCR5 inhibitors in HIV and beyond. Journal of Translational Medicine 2010 9(Suppl 1):S9.

\section{Submit your next manuscript to BioMed Central and take full advantage of:}

- Convenient online submission

- Thorough peer review

- No space constraints or color figure charges

- Immediate publication on acceptance

- Inclusion in PubMed, CAS, Scopus and Google Scholar

- Research which is freely available for redistribution

Submit your manuscript at www.biomedcentral.com/submit
C Biomed Central 